\title{
Application of The Chain Code and Fourier Analysis Techniques for The Investigation of Wrinkles and Distortions on Early Flames
}

\author{
A. R. A. Aziz ${ }^{1}$, F. Y. Hagos ${ }^{2,3^{*}}$, Y. T. Anbese ${ }^{1}$, M. R. Heikal ${ }^{4}$ and Firmansyah $^{1}$ \\ ${ }^{1}$ Center for Automotive Research and Electric Mobility (CAREM), \\ Universiti Teknologi Petronas, 31750 Tronoh, Perak, Malaysia \\ ${ }^{2}$ Advanced Fluids Focus Group (AFFG), Faculty of Mechanical Engineering, \\ Universiti Malaysia Pahang, 26600, Pekan, Pahang, Malaysia \\ *Email: ftwi@ump.edu.my \\ Phone: +6094246367; Fax: +6094246222 \\ ${ }^{3}$ Automotive Engineering Center (AEC), Universiti Malaysia Pahang, 26600, Pekan, \\ Pahang, Malaysia, \\ ${ }^{4}$ School of Computing, Engineering and Mathematics, University of Brighton
}

\begin{abstract}
The study of flame commencement and growth in SI engine has attracted the attention of many researchers due to its strong dependence to the in-cylinder flow and its capability to influence flame propagation characteristics in SI engines. Optical visualisation has been one of the prominent techniques utilized in this study of the early flame properties. This work shows the application of Elliptic Fourier analysis (EFA) and image processing tools for the investigation of the early flame details from its shape features. An endoscopic ICCD camera was used to capture the flame images, at an interval of $2^{\circ} \mathrm{CA}$ starting from ignition onset for a period of $30^{\circ} \mathrm{CAs}$ (about $3 \mathrm{~ms}$ ), from a CNG DI single cylinder SI engine operation in stratified and homogeneous charge conditions. The intake configuration was adjusted to acquire tumble or swirl induction, and engine speed was made to vary between 1500 and $2100 \mathrm{rpm}$. The sequences of collected images were processed to investigate wrinkles, distortion and growth rate of the early flame within the $3 \mathrm{~ms}$ combustion duration. Some tools of image processing, such as intensity enhancement, filtering, thresholding and boundary tracing, were applied. Once the flame boundary identified, it was chain coded, and elliptic Fourier function was utilised to characterise the contour. For this purpose, a computer programming code was proposed by the authors for automatic processing of the flame image data. The application of the elliptic Fourier analysis was found useful in the investigation of the early flame characteristics from its shape features; led to the portrayal of wrinkles and distortion levels quantitatively in a simpler way.
\end{abstract}

Keywords: Chain code; elliptic Fourier analysis; image processing; wrinkles; early flame.

\section{INTRODUCTION}

The study of early flames in SI engine is important to investigate the interrelation of flame propagation with combustion performance and exhaust emissions. A better flame development improves combustion, which results in better fuel efficiency and reduced unburned hydrocarbon emissions [1]. 
Flame development period in an SI engine can be defined as the period in which up to $10 \%$ of the fuel mass burned. The flame kernel growth is mainly dominated by the ignition system property when the flame is below $1 \mathrm{~mm}$ radius. The kernel expansion rate is more controlled by the balance between laminar flame speed and strain rate up to the size of $2 \mathrm{~mm}$ radius. Then after the flame kernel starts to interact with the surrounding incylinder turbulent flow field. The fully developed flame structure property is acquired when the size reaches about $10 \mathrm{~mm}$ and in this period, the fuel fraction burned may reach up to $10 \%$ of the total mass [2].

Flame visualisation and experimental study of flame characteristics may require recording of the flame data directly or indirectly by imaging devices [3]. The light source for the illumination purpose can be the natural luminosity of the flame itself or an external light source such as a high-power laser [4]. The direct imaging can be done by flame region identification using the Planar Laser-Induced Fluorescence (PLIF) method by imaging exited radicals of combustion gas products. The imaging is at an appropriate laser wavelength, such as $\mathrm{OH}$ at $266 \mathrm{~nm}$, or application of two-dimensional Mie scattering method to image seed particles in the flow outside the flame region because of the burning up of the seed particles in the flame region. The application of these methods for early flame imaging in which the small flame is wandering around by the flow in the cylinder is very difficult. The laser sheet must intersect the flame to get the flame boundary. Having a laser sheet at a specific location and small flame wandering here and there depending on the nature of the flow, it is very difficult to implement laser tomography for this specific study. Besides, applying laser tomography method for initial flame kernels could be impractical due to the nature of flame orientation In an actual engine combustion scenario [5]. Since the flame in the early stage of development is very small in size, it can be easily taken away from the spark centre by the surrounding airflow. This random position of the flame kernel attempts capturing it with a laser sheet very challenging [6].

Fibre-optic instrumented spark plug (FOSP) is one of the available techniques used to study flame kernel growth rate, as has been used by Ancimer et al. [7, 8]. This technique works with the recording of flame arrival time by the eight fibre-optics implemented at the periphery of the spark plug tip. Mathematical models are essential to construct 2-D flame kernel boundary from the arrival time signals. The most adopted models in this area are; an elliptic fit model that was developed by Kerstein and Witze [9], and the cubic-spline model by Lord et al. [10]. Since the model prediction lacks boundary details, this technique is not capable of identifying flame wrinkles and distortion correctly.

Chemiluminescence and Schlieren imaging are still other possible techniques to apply for flame visualisation. Chemiluminescence technique depends on the imaging of electromagnetic radiation signal from combustion radicals because of the chemical reaction. In the investigation of the early flame kernel, this signal is too weak to identify clear flame boundaries as discussed in [11]. On the other hand, the Schlieren method has limited application in quantitative analysis of flame characteristics [12]; besides, it demands a large visualisation window on the engine cylinder.

The choice of the techniques especially in SI engine applications boiled down to direct visualisation method. Direct visualisation method is the imaging of the early flame using its luminosity by CCD or high-speed camera. With the increase in technical capability of CCD cameras, image intensifiers and high frame rate video cameras, direct imaging of weak flames for quantitative analysis become more apparent. The high dynamic ranges of modern CCD cameras incorporated with the advancement of image 
processing technology maximise the capability of the direct visualisation technique for flame kernel study [13]. With the presence of too much noise in the engine and the weak signal of the early flame kernel growth, interpretation of the flame behaviour and characteristics is the major challenge. The basic morphological parameters to be considered in the visualisation of the flame kernel description are the wrinkles level of the flame front and the global flame distortion. These physical parameters mainly influence the flame growth rate. The aim of this study is, therefore, to utilise chain code and elliptic Fourier analysis (EFA) tools to investigate the characteristics of the early flame development from its shape features.

\section{METHODS AND TECHNIQUES}

\section{Image Acquisition}

Experimental work was performed to investigate wrinkles and distortion effects on the flame kernel caused by a change in engine speed and induction flow structures using the technique discussed earlier. A chain code and elliptic Fourier analysis (EFA) was used to analyses the flame wrinkles and distortion. A single cylinder direct injection engine was made to operate at partial load using CNG fuel injected at 18 bars. The fuel injection was set at $90^{\circ}$ before the top dead centre (BTDC) for the stratified charge and $180^{\circ}$ BTDC for the homogeneous charge cases. The air-fuel ratio was controlled at the lean condition in both stratified and homogeneous charge combustion model [14]. The engine speed considered in the current study is from 1500-2100 rpm. Early flame development visualisation is challenging at lower end performance with the engine speed lower than $3000 \mathrm{rpm}$ as the luminosity of the flame is low [15]. The imaging system used was a HiSence 12 bit CCD camera equipped with Hamamatsu CA2098 image intensifier and AVL KARL STORZ M00060 $30^{\circ}$ endoscope to capture the flame image from the combustion chamber through a $10 \mathrm{~mm}$ hole on the cylinder head, as the installation shown in Figure 1 and the arrangement schematics in Figure 2.

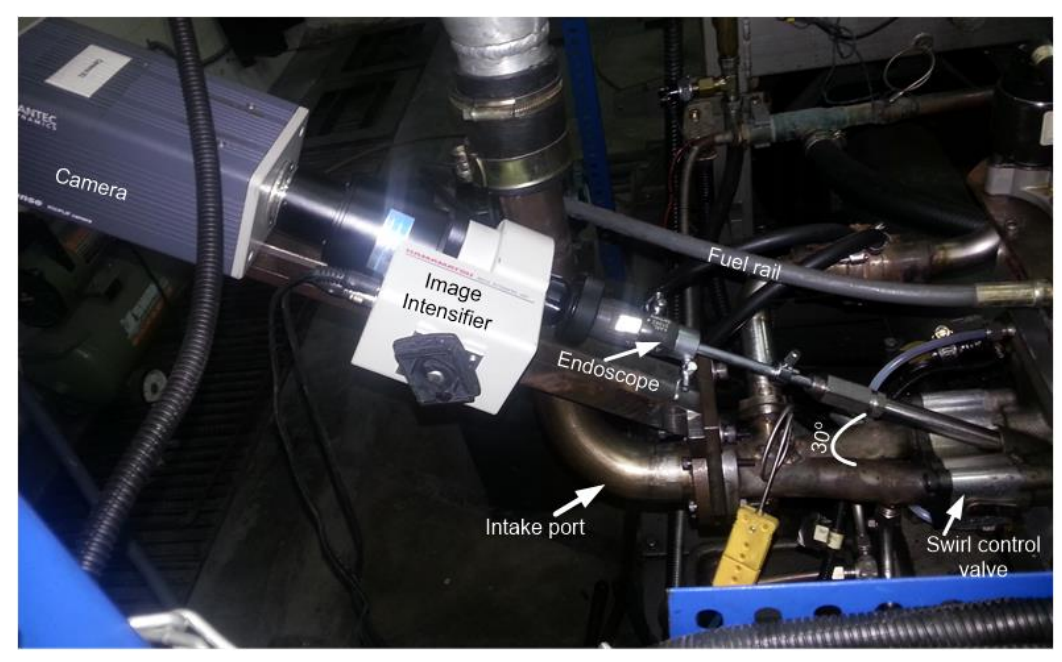

Figure 1. The imaging device fixed on the engine at an installation angle of $30^{\circ}$. 


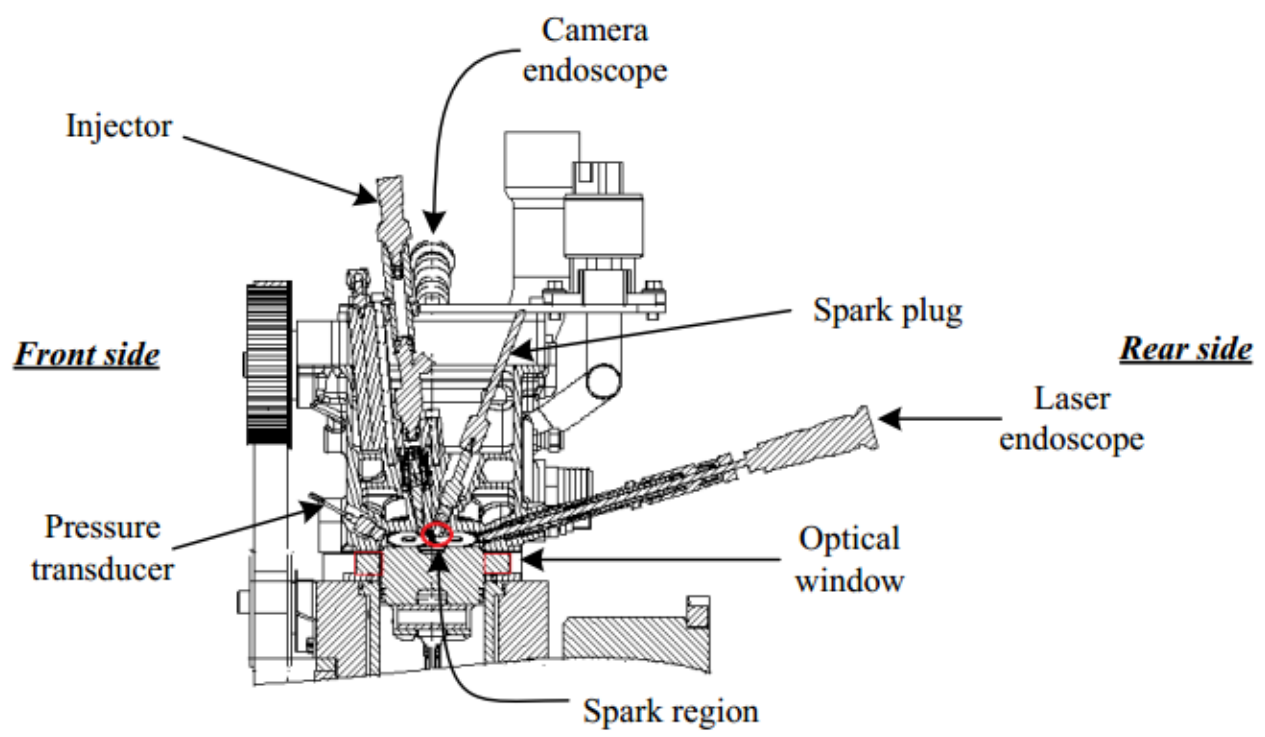

(a)

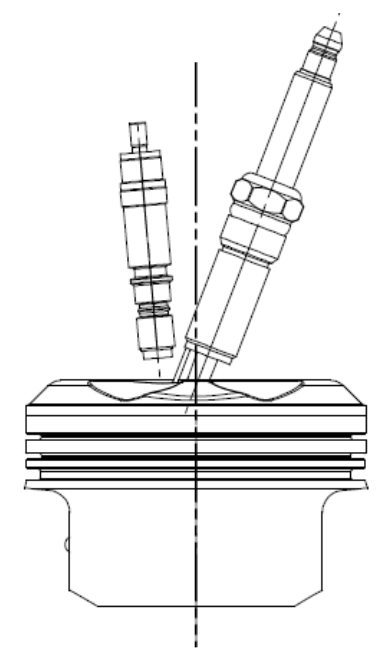

(b)

Figure 2. The CNG DI engine with the endoscopic optical access (a) complete and (b) clear cross-section of the piston along with injector and spark plug arrangement.

The main consideration in the image acquisition system was the synchronisation of the imaging system with that of the engine operating speed and top dead centre (TDC) position sensors. The synchronisation of the external camera trigger signal by using the cam position as in input with the crank angle and TDC signal by the use of LabVIEW control program [16]. Figure 3 shows the schematics of all the sensors, the camera and the data acquisition system used in the current experiment. 


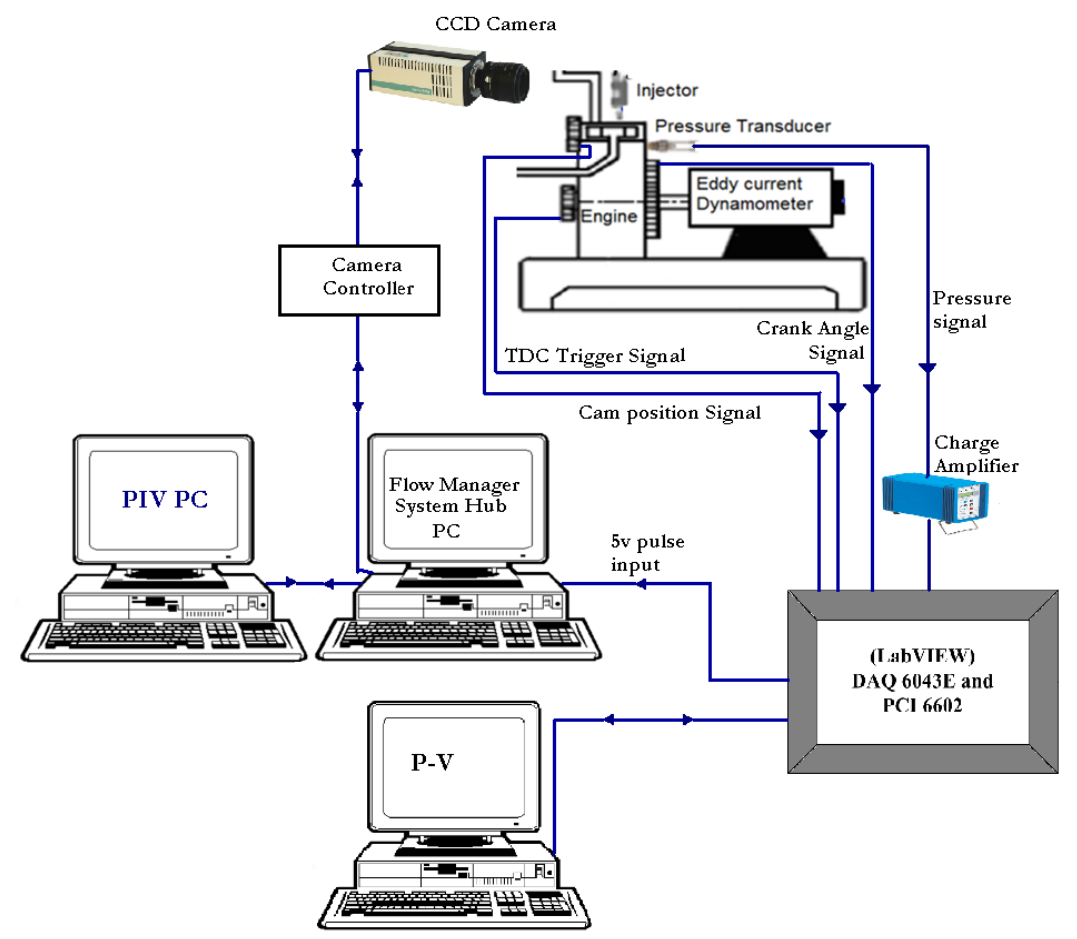

Figure 3. Flame imaging setup [16].

The crank angle sensor generated a signal tick for every $0.5^{\circ}$ rotation of the crank producing a total of 1440 ticks for every complete cycle (two revolutions). Out of this, another signal tick (TDC trigger) was generated by the crank angle sensor for every revolution. However, this signal could not match with the exact position of TDC due to the difficulty encountered during engine assembly. Therefore, there was an offset of $126.5^{\circ} \mathrm{CA}$ between the TDC trigger signal and the exact TDC position, which was taken to be an initial delay in the calculation of the TDC position [17].

The TDC trigger signal was generated twice every complete cycle, one at the end of the exhaust stroke and the other at the end of compression stroke. Identification of the TDC at the end of the compression stroke was very important to define the exact position of the external camera triggering signal. The camshaft sensor with the help of the crank angle sensor was used to define the TDC position. This sensor was attached to camshaft wheel, and its signal was generated in every complete cycle. This signal was positioned at $31.5^{\circ}$ after the compression stroke TDC. These all three signals were calibrated and synchronised with the help of a four-channel oscilloscope. Figure 4 shows the signal synchronisation of different sensors used for flame imaging.

LabVIEW program was used to control the external camera triggering position taking the crank angle and cam position signals as an input from NI-DAQ system. Flame image was then captured starting from the onset of ignition for $20^{\circ} \mathrm{CA}$ at an interval of $2^{\circ} \mathrm{CA}$. A total of 30 flame images were captured at every required crank angle in order to get the average properties of the developing flame for that specific crank angle [16]. 


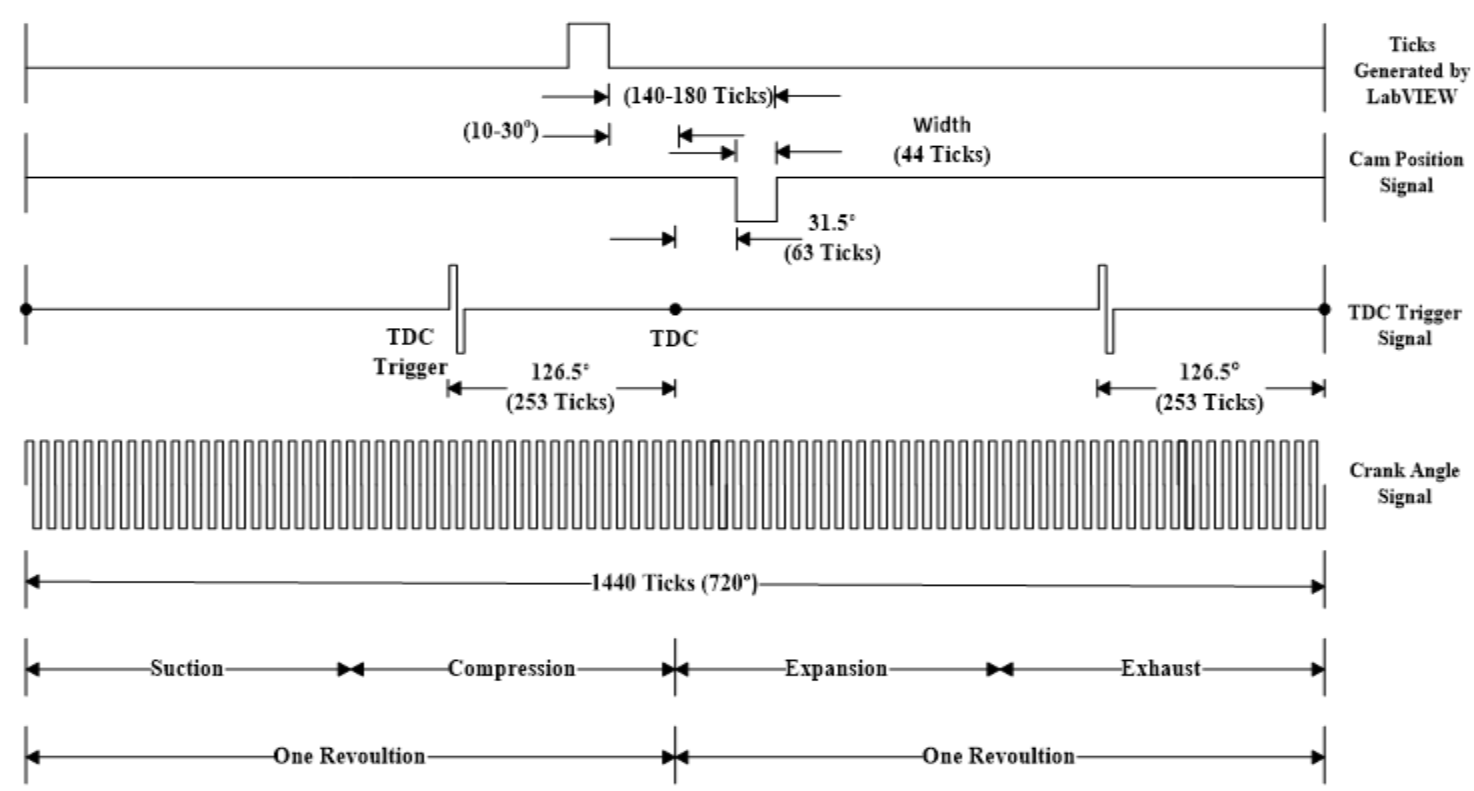

Figure 4. Signal synchronisation of different sensors for flame imaging.

\section{Image Filtering}

Early flame kernels are flames of small sizes, about $5 \mathrm{~mm}$ radius, with intensity too weak to be visualised. In such case, digital imaging using CCD cameras have immense contribution to get the weak intensity flame visualized due to their high dynamic ranges. From these images, meaningful physical information can be derived through image processing and Fourier transform applications.

Noise in digital imaging is unavoidable occurrences. Noise can occur during image capturing, transmission or processing. The thermoelectric cooling system in modern CCD cameras minimises thermal noises due to rise in temperature. Therefore, the first task to be considered in the flame image analysis can be the removal of noises from the images using digital filters. This leads to the implementation of a 2-D convolution of a filter function directly on the image in the spatial domain. For a square filter kernel size $\mathrm{M} \times \mathrm{M}$ with input image $\mathrm{f}(\mathrm{m}, \mathrm{n})$ and filter function $\mathrm{G}(\mathrm{x}, \mathrm{y})$, the output image is given by:

$$
g(m, n)=\sum_{x=-\frac{M}{2}}^{\frac{M}{2}} \sum_{y=-\frac{M}{2}}^{\frac{M}{2}} G(x, y) f(m-x, n-y)
$$

The filter function used in this work was the 2-D Gaussian weighted average given by,

$$
\mathrm{G}(\mathrm{x}, \mathrm{y} ; \sigma)=\frac{1}{2 \pi \sigma^{2}} \mathrm{e}^{-\frac{\mathrm{x}^{2}+\mathrm{y}^{2}}{2 \sigma^{2}}}
$$

where, $\sigma$ is the standard deviation of the Gaussian function. 


\section{Image Binarisation}

Binarisation is a process of segmenting an image into an object and a background according to the gray level of image pixels using a specific threshold value. Pixels of the binary image categorised as black or white, or a logical value of ' 1 ' or ' 0 '.

The important step in binarisation is to find the appropriate marginal value that can separate the foreground (or the object) from the background effectively. Sezgin and Sakur [18] made a comprehensive evaluation of around 40 thresholding techniques by categorising them into six groups according to their thresholding performance. The criteria they considered for every thresholding method were classification error, edge mismatch, relative foreground area error, modified Hausdorff distance, and region nonuniformity. Out of the evaluated techniques, the histogram based Ostu thresholding method showed better performance, and due to its simplicity, it has been the most applied in the image segmentation process.

Ostu thresholding technique was first introduced by N. Otsu in late 1970's [19], and has been used for decades for image segmentation process in many areas; such as weld defect identification of radiographic images [20], and plant leaf classification [21]. It uses the statistics of the pixel intensity to identify threshold value in generating the binary images. Its simplicity to implement in an efficient algorithm for multiple images in an automatic segmentation process makes Ostu thresholding the most preferred method.

The Ostu thresholding technique depends on the statistical distribution of graylevel values of the image pixels. Assume a total of L gray levels represents the pixels intensity, and the number of pixels in the $\mathrm{i}^{\text {th }}$ gray level is denoted by $\mathrm{h}_{\mathrm{i}}$. With $\mathrm{N}$ to be the total number of image pixels, the probability of a pixel to be in the $\mathrm{i}^{\text {th }}$ gray level is given by,

$$
\mathrm{P}_{\mathrm{i}}=\frac{\mathrm{h}_{\mathrm{i}}}{\mathrm{N}}
$$

Now, let us classify pixels of the image into two classes; background and foreground. The background class contains pixels with gray level values range 0 to $\mathrm{k}$, and the foreground class contains pixels of gray level range $\mathrm{k}$ to $(\mathrm{L}-1)$, in which $\mathrm{k}$ is the threshold value. Thus, the probability of class occurrence $(\omega)$, class mean $(\mu)$ and class variance $\left(\sigma^{2}\right)$ is given by:

$$
\begin{aligned}
& \omega_{0}=\sum_{i=0}^{k} P_{i} ; \quad \omega_{1}=\sum_{i=k+1}^{L-1} P_{i}=1-\omega_{0} \\
& \mu_{0}=\sum_{i=0}^{k} \frac{i P_{i}}{\omega_{0}} ; \quad \mu_{1}=\sum_{i=k+1}^{L-1} \frac{i P_{i}}{\omega_{1}} \\
& \sigma_{0}^{2}=\sum_{i=0}^{k}\left(i-\mu_{0}\right)^{2} P_{i} ; \quad \sigma_{1}^{2}=\sum_{i=k+1}^{L-1}\left(i-\mu_{1}\right)^{2} P_{i}
\end{aligned}
$$




$$
\mu_{\mathrm{T}}=\sum_{\mathrm{i}=0}^{\mathrm{L}-1} \mathrm{iP}_{\mathrm{i}} ; \quad \sigma_{\mathrm{T}}^{2}=\sum_{\mathrm{i}=0}^{\mathrm{L}-1}\left(\mathrm{i}-\mu_{\mathrm{T}}\right)^{2} \mathrm{P}_{\mathrm{i}}
$$

where subscripts 0,1 and $\mathrm{T}$ represent background, foreground and total classes, respectively. To identify the optimum threshold, it is important to look at the betweenclass variance;

$$
\sigma_{\mathrm{B}}^{2}=\omega_{0}\left(\mu_{0}-\mu_{\mathrm{T}}\right)^{2}+\omega_{1}\left(\mu_{1}-\mu_{\mathrm{T}}\right)^{2}
$$

A threshold value that maximises the between-class variance $\left(\sigma_{\mathrm{B}}^{2}\right)$ is considered as the optimum threshold value for the formation of binary images, as discussed in [19]. Therefore, the optimum threshold value $\mathrm{k}$ is the one that gives maximum $\sigma_{\mathrm{B}}^{2}$ for $1 \leq \mathrm{k} \leq \mathrm{L}$.

\section{Flame Boundary Tracing}

The pixels of the binary flame images identified by the Ostu thresholding method have a logical expression that can be black for object and white for the background or can be quantified as ' 1 ' for the object (foreground) and ' 0 ' for the background. For further flame image analysis, the boundary pixels of the flame images had to be identified using Mooreneighbor tracing method. The algorithm is simple and can be implemented on the Matlab platform. It works by scanning the binary image along the columns starting from bottom left until the first object pixel (or ' 1 ') is found. Then, returning to the immediate previous background pixel and trace clockwise around the neighbourhood of the object pixel identified earlier until another object pixel found. The algorithm terminates tracing when the first object pixel is met for the second time. Finally, the coordinates of all the pixels that constitute the closed boundary of the flame are identified.

\section{Elliptic Fourier Analysis and Chain Codes}

Elliptic Fourier analysis was first introduced by Kuhl and Giardina in the '80s [22]. Since then it has been used in many identification and classification applications in plant and animal species studies [23, 24], and human anatomy studies [25]. The coefficients of EFA are functions of the shape of the flame boundary under consideration. The coefficients can be size invariant so that they define shape character in spite of size variations of an object. This code is very effective for data reduction process by minimising the boundary points used for reconstruction without affecting the ultimate shape, and also able to avoid details of the boundary by changing the harmonic levels.

Chain coding is widely used as a standard input format for image shape description algorithms, such as EFA. It describes a 2-D image boundary via 1-D directional codes by forming a series of connected straight-line segments. H. Freeman [26] was the first to create this code, and his principle was based on the idea that any continuous curve can be represented by many small straight line segments and angles describing their directions. Any desired precision of curve prediction by the chain code can be obtained with a coarse angle representation and arbitrarily small distances of line segments.

The Freeman chain-code, which is named after the inventor, can be constructed using 4-directional or 8-directional codes. The 8-directional code considers all the neighbouring pixels, and it is the most preferred to code any closed boundary. The codes 
that represent the segmented lines are given by 01234567 , and each code represents a specific direction of traversing to the next pixel throughout the boundary of the binary image until it returns to the starting pixel as illustrated in Figure 5. The segment size can be taken to be the step to the next pixel on the image boundary, which is equal to either 1 or $\sqrt{2}$ pix. The outputs of the chain code are used as standard inputs for the EFA algorithm.

\begin{tabular}{|c|c|c|}
\hline$\Delta \mathbf{x}$ & $\mathbf{\Delta y}$ & $\mathbf{8}$-code \\
\hline 1 & 0 & 0 \\
\hline 1 & 1 & 1 \\
\hline 0 & 1 & 2 \\
\hline-1 & 1 & 3 \\
\hline-1 & 0 & 4 \\
\hline-1 & -1 & 5 \\
\hline 0 & -1 & 6 \\
\hline 1 & -1 & 7 \\
\hline
\end{tabular}
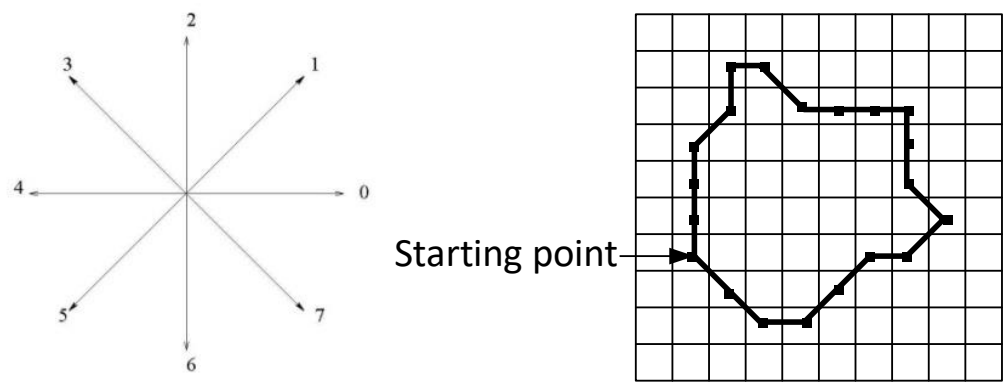

Figure 5. Eight-directional Freeman chain code and depiction of the typical boundary of an image expressed by the code 22212070006675455433 [27].

Elliptic Fourier coefficients maintain a description of object boundary in a twodimensional space of the complex plane in which real and imaginary components represent each pixel in the image space. Thus, a curve in the closed boundary can be defined as:

$$
c(t)=X(t)+j Y(t)
$$

where $t$ is the arc length. Based on the general complex plane representation of curves by Eq. (9), it is possible to identify the Elliptic Fourier coefficients through Fourier series expansion. After some analysis, as detailed in the work presented by Nixon and Aguado (2008) [28], the $x$ and y coordinates of the boundary points at $t$ can be represented by the sum of the elliptic Fourier series:

$$
\begin{aligned}
& \mathrm{x}_{\mathrm{N}}(\mathrm{t})=\mathrm{A}_{0}+\sum_{\mathrm{n}=1}^{N} \mathrm{a}_{\mathrm{n}} \cos \left(\frac{2 \mathrm{n} \pi \mathrm{t}}{\mathrm{T}}\right)+\mathrm{b}_{\mathrm{n}} \sin \left(\frac{2 \mathrm{n} \pi \mathrm{t}}{\mathrm{T}}\right) \\
& \mathrm{y}_{N}(\mathrm{t})=\mathrm{C}_{0}+\sum_{\mathrm{n}=1}^{N} \mathrm{c}_{\mathrm{n}} \cos \left(\frac{2 \mathrm{n} \pi \mathrm{t}}{\mathrm{T}}\right)+\mathrm{d}_{\mathrm{n}} \sin \left(\frac{2 \mathrm{n} \pi \mathrm{t}}{\mathrm{T}}\right)
\end{aligned}
$$

where the arc-length $t$ is the step required to traverse one pixel along the closed contour; $\mathrm{t}_{\mathrm{p}-1}<\mathrm{t}<\mathrm{t}_{\mathrm{p}}$ for $1 \leq \mathrm{p} \leq \mathrm{k}$; $\mathrm{k}$ is the total number of codes describing the boundary contour; $\mathrm{n}$ is the number of Fourier series or the level of harmonics; $T$ is the basic period of the chaincode, that is $\mathrm{T}=\mathrm{t}_{\mathrm{k}} ; \mathrm{A}_{0}$ and $\mathrm{C}_{0}$ are the bias coefficients. Setting $\mathrm{A}_{0}$ and $\mathrm{C}_{0}$ to be zero makes the center of the region under the closed boundary to be at the center of coordinate axis.

The use of higher harmonic levels increases the description of details of the flame boundary in the reconstruction process. Lower frequencies, which contain the general feature of the boundary shape, are described by the lower harmonics; as a result, the total number of Fourier coefficients used to define the boundary is reduced. This technique 
was found to be efficient in the approximation of the mean flame contour to quantify the level of the contour wrinkles. On the other hand, the high frequency details of the flame contour structure are revealed by the higher harmonic level reconstruction. The Fourier coefficients appeared in Eq. (10) and (11), at the $\mathrm{n}^{\text {th }}$ harmonic level are obtained from;

$$
\begin{aligned}
& \mathrm{a}_{\mathrm{n}}=\frac{\mathrm{T}}{2 \mathrm{n}^{2} \pi^{2}} \sum_{\mathrm{p}=1}^{\mathrm{k}} \frac{\Delta \mathrm{x}_{\mathrm{p}}}{\Delta \mathrm{t}_{\mathrm{p}}}\left[\cos \left(\frac{2 \mathrm{n} \pi \mathrm{t}_{\mathrm{p}}}{\mathrm{T}}\right)-\cos \left(\frac{2 \mathrm{n} \pi \mathrm{t}_{\mathrm{p}-1}}{\mathrm{~T}}\right)\right] \\
& \mathrm{b}_{\mathrm{n}}=\frac{\mathrm{T}}{2 \mathrm{n}^{2} \pi^{2}} \sum_{\mathrm{p}=1}^{\mathrm{k}} \frac{\Delta \mathrm{x}_{\mathrm{p}}}{\Delta \mathrm{t}_{\mathrm{p}}}\left[\sin \left(\frac{2 \mathrm{n} \pi \mathrm{t}_{\mathrm{p}}}{\mathrm{T}}\right)-\sin \left(\frac{2 \mathrm{n} \pi \mathrm{t}_{\mathrm{p}-1}}{\mathrm{~T}}\right)\right] \\
& \mathrm{c}_{\mathrm{n}}=\frac{\mathrm{T}}{2 \mathrm{n}^{2} \pi^{2}} \sum_{\mathrm{p}=1}^{\mathrm{k}} \frac{\Delta \mathrm{y}_{\mathrm{p}}}{\Delta \mathrm{t}_{\mathrm{p}}}\left[\cos \left(\frac{2 \mathrm{n} \pi \mathrm{t}_{\mathrm{p}}}{\mathrm{T}}\right)-\cos \left(\frac{2 \mathrm{n} \pi \mathrm{t}_{\mathrm{p}-1}}{\mathrm{~T}}\right)\right] \\
& \mathrm{d}_{\mathrm{n}}=\frac{\mathrm{T}}{2 \mathrm{n}^{2} \pi^{2}} \sum_{\mathrm{p}=1}^{\mathrm{k}} \frac{\Delta \mathrm{y}_{\mathrm{p}}}{\Delta \mathrm{t}_{\mathrm{p}}}\left[\sin \left(\frac{2 \mathrm{n} \pi \mathrm{t}_{\mathrm{p}}}{\mathrm{T}}\right)-\sin \left(\frac{2 \mathrm{n} \pi \mathrm{t}_{\mathrm{p}-1}}{\mathrm{~T}}\right)\right]
\end{aligned}
$$

where, $\Delta \mathrm{t}_{\mathrm{p}}=\sqrt{\Delta \mathrm{x}_{\mathrm{p}}^{2}+\Delta \mathrm{y}_{\mathrm{p}}^{2}}$ and $\mathrm{t}_{\mathrm{p}}=\sum_{\mathrm{i}=1}^{\mathrm{p}} \Delta \mathrm{t}_{\mathrm{i}}$ in which $\Delta \mathrm{x}_{\mathrm{p}}$ and $\Delta \mathrm{y}_{\mathrm{p}}$ are the spatial changes in the respective axis that can be identified from the chain code at point $p$ of the flame contour. $\Delta t_{p}$ is the step change that is required to travel from point $(\mathrm{p}-1)$ to $\mathrm{p}$ in the chain code. $t_{p}$ is the total number of steps required to travel up to point $p$ in the chain code.

The elliptic Fourier coefficients contain non-redundant information. They can uniquely describe shapes of closed contours by representing dimensions of the ellipse at each harmonic level, as illustrated in Figure 6.

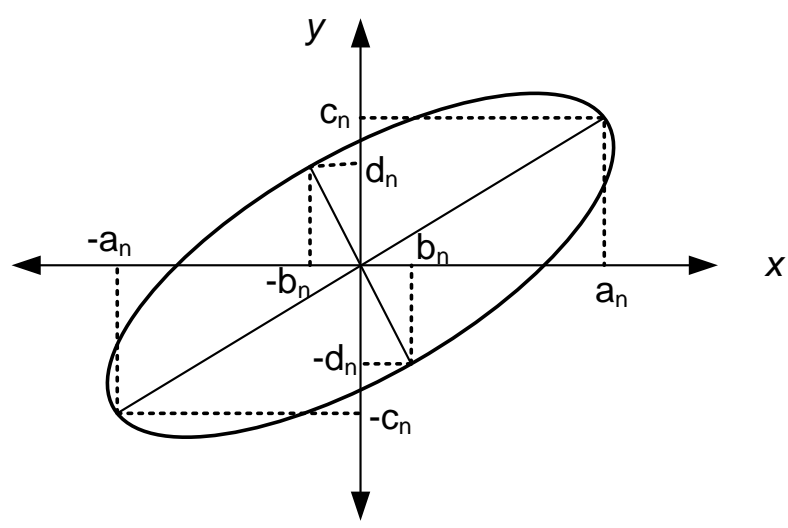

Figure 6. Representation of the Fourier coefficients in the harmonic ellipses.

The $x$ - and y-coordinates are computed separately using Eq. (10) to (15), and the shape of the object can be recreated by combining these coordinates for identical value of $\mathrm{t}$, as shown in Figure 7. As discussed earlier, the elliptic Fourier coefficients represent an ellipse at any level of harmonic. The ellipses at lower harmonic levels are bigger to 
describe the general shape of the boundary. As the harmonic level increases the size of the harmonic ellipse drops, and thus the details of the flame contour will be revealed. The sum of the series of harmonic ellipses at the different levels converges into a polygon that represents the given contour, as portrayed in Figure 8 for a typical flame. The level of harmonics defines the features of the reconstructed flame contour. The higher the harmonic levels, the higher the chance of revealing contour details. Figure 9 shows the reconstructed flame contour of the typical flame image shown in Figure 8(a) at different harmonic levels; the exact reconstruction of the flame contour was found at the $120^{\text {th }}$ harmonic level. Table 1 shows the Fourier descriptors of the first ten harmonic levels.

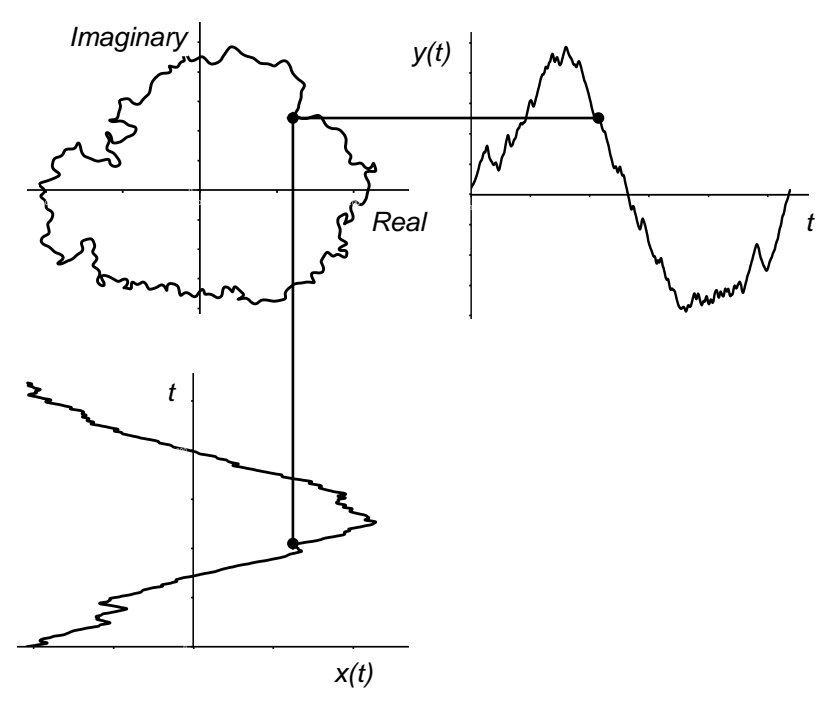

Figure 7. The complex curve representation from the two coordinates.

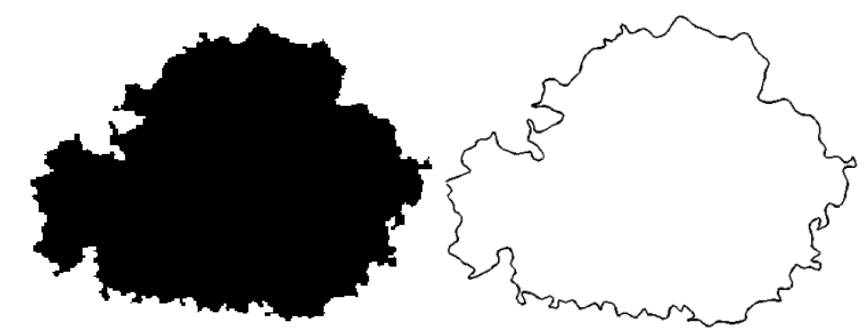

(a)

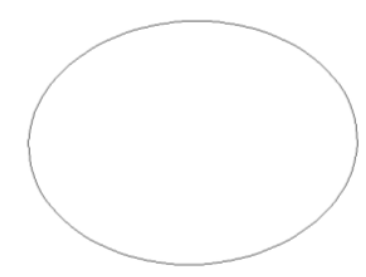

(b)

Figure 8. (a) Binary image of a typical flame and its contour (b) Harmonic ellipses for the first 10 harmonic levels of the flame boundary shown in (a). 


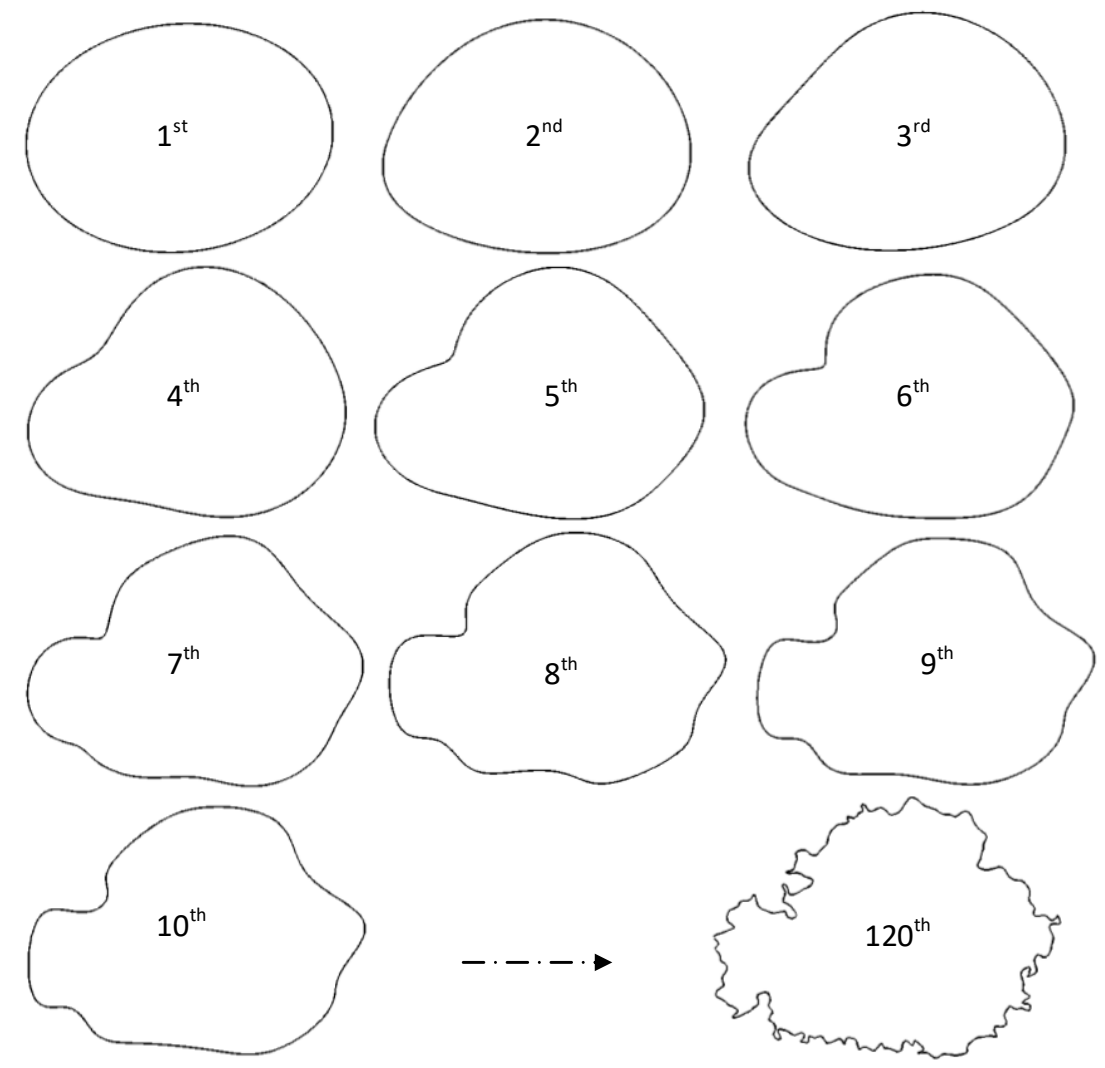

Figure 9. Reconstructed flame contour at different harmonic levels.

Table 1. Fourier descriptors of the first ten harmonic levels.

\begin{tabular}{ccccc}
\hline $\begin{array}{c}\text { Harmonic } \\
\text { level }\end{array}$ & $\mathrm{a}_{\mathrm{n}}$ & $\mathrm{b}_{\mathrm{n}}$ & $\mathrm{c}_{\mathrm{n}}$ & $\mathrm{d}_{\mathrm{n}}$ \\
\hline 1 & -96.9337 & -0.4725 & -4.7904 & 76.2928 \\
2 & 7.4116 & 4.2382 & -4.2777 & -9.0534 \\
3 & -2.0552 & 4.6294 & 4.9356 & -0.0781 \\
4 & -3.8106 & 2.0718 & 3.4938 & 5.6907 \\
5 & -3.9951 & 0.6284 & 0.1699 & 1.579 \\
6 & -1.4266 & 2.0469 & 1.1297 & 2.9539 \\
7 & -1.4179 & -1.924 & 0.1514 & 2.1478 \\
8 & 1.2555 & -2.0859 & 1.3608 & 0.8021 \\
9 & 0.8262 & 1.2002 & 0.9225 & 1.514 \\
10 & -0.2626 & -0.1611 & 0.5201 & 0.4741 \\
\hline
\end{tabular}

Reconstruction of flame contours using EFA is performed by summing up a series of harmonic ellipses, like the one shown in Figure 8(b). The extent to which the wrinkles detail of the contour to be included in the reconstruction depends on the number of harmonic levels considered. Such details of the flame boundary are achieved by the inclusion of the small-sized harmonic ellipses whose major radius is less than $1 \%$ of the equivalent flame radius, as observed from the analysis of few flame images. Therefore, the $1 \%$ threshold was set to be the cut-off harmonic level to identify the mean contour. Figure 10 shows the mean contour of a typical flame identified by the $1 \%$ threshold value superimposed on the wrinkled flame contour. Once the mean flame is identified the 
wrinkles level can be approximated from the standard deviation (STD) of the displacements of the boundary points from the mean to the wrinkled flame contour.

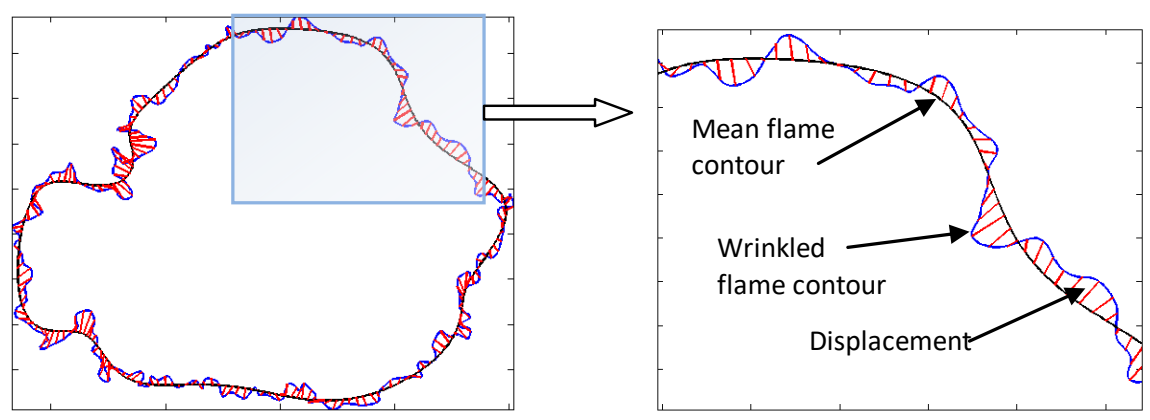

Figure 10. Mean flame contour superimposed on the wrinkled one.

\section{ANALYSIS AND DISCUSSION}

A total of 30 flame images were collected at every set crank angle with a $2^{\circ} \mathrm{CA}$ interval starting from $0.5^{\circ} \mathrm{CA}$ after ignition onset $\left(38^{\circ} \mathrm{CA}\right.$ BTDC) up to $10^{\circ} \mathrm{CA}$ BTDC. The series of collected images portrayed the development stage of the flame kernel within $3 \mathrm{~ms}$ after ignition onset. The authors developed a computer code to examine a large number of collected flame images quantitatively in an automatic manner. The flame wrinkles level, distortion and growth rate in the early development stage were the parameters investigated by the technique discussed earlier in this work.

\section{Flame Wrinkles}

Figure 11 shows the degree of wrinkles obtained for the tumble and swirl induction for both stratified and homogeneous charge combustions at different engine operating speeds ranging from 1500 to $2100 \mathrm{rpm}$. The wrinkling level was identified from the standard deviation of the Euclidean distances between similar boundary points of mean flame and turbulent flame contours. The fundamental wrinkles formation behaviour was shown differently in stratified and homogeneous charge combustion cases. In the stratified charge combustion, both tumble and swirl inductions exhibited the occurrence of a direct relation between wrinkles formation and engine speed; whereas, homogeneous charge combustion showed the opposite.

The level of small-scale turbulence and the air-fuel ratio at the surrounding of the spark electrode play a major role in the formation of wrinkles on the early flames [2]. A higher degree of wrinkles could be exhibited with lean fuel-air due to the relatively lower burn rate as compared to the wrinkling rate caused by turbulence. Then again, increasing of the engine speed could increase the turbulence intensity inside the cylinder [29, 30], which facilitates the flame wrinkles formation [31]. Therefore, it can be affirmed that the trade-off between the fuel-air mixture leanness and the degree of turbulence caused as a result of variation of engine operating speed at the time of ignition is the determinant factors of the level of the early flames shown in Figure 11. The maximum degree of wrinkles is observed in the early flames in the homogeneous charge combustion with an engine speed of $1500 \mathrm{rpm}$. The fact that the local fuel-air ratio of the mixture is richer or close to stoichiometric near the spark electrode region with a stratified charge, the degree of wrinkles tends to increase with an increase in engine speed [27]. 


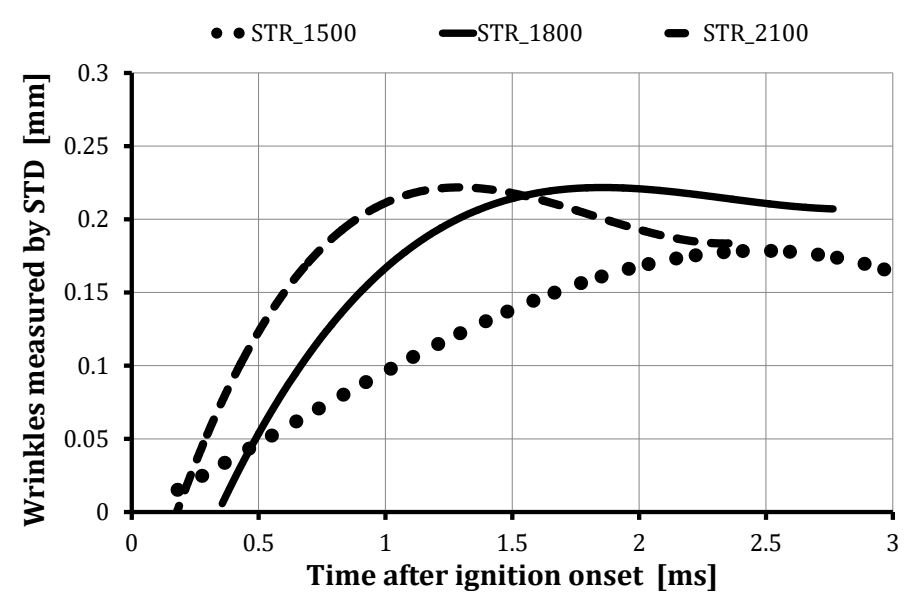

(a)

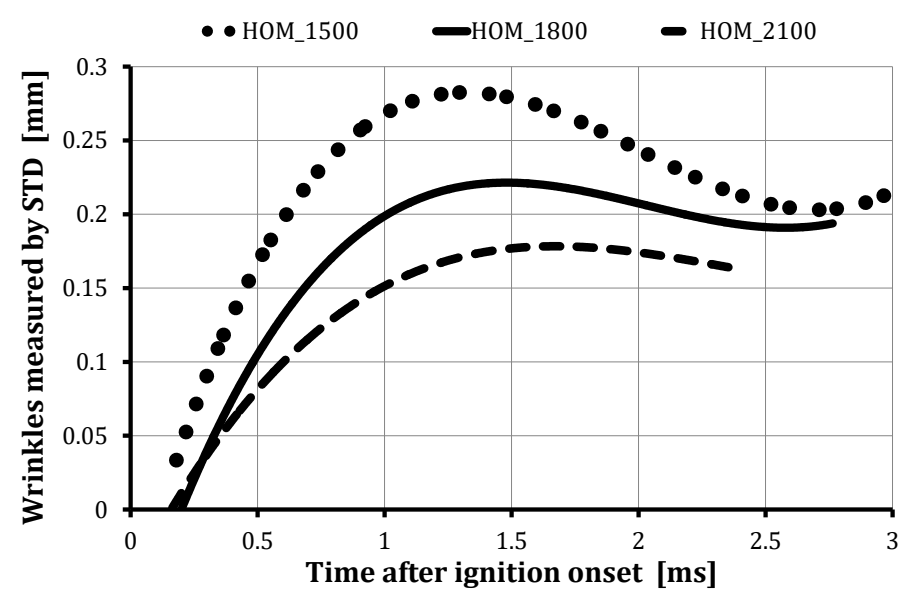

(b)

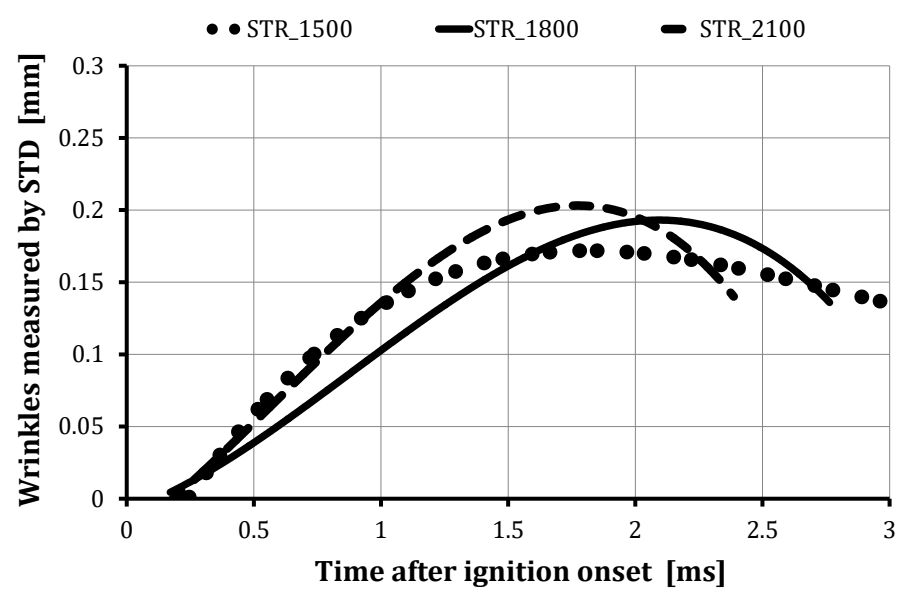

(c) 


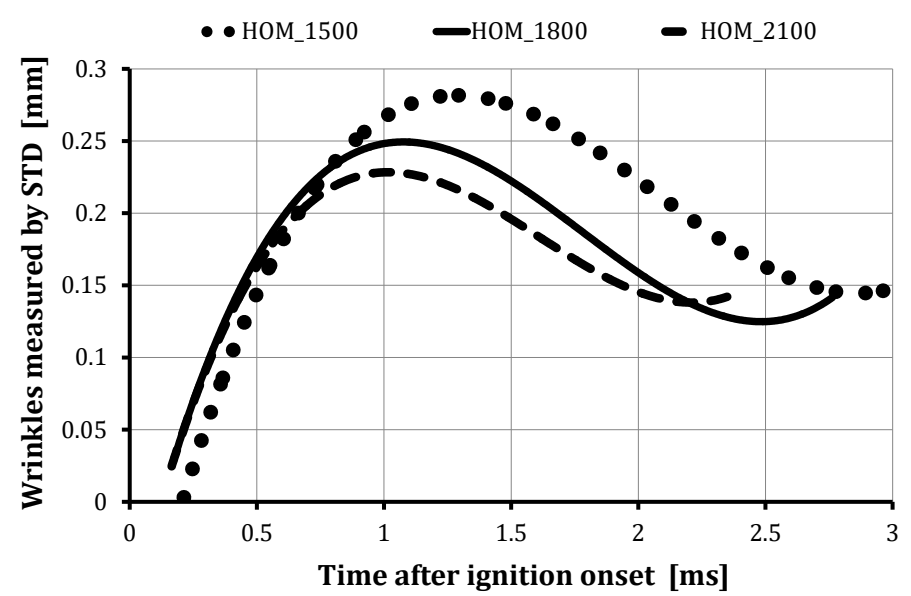

(d)

Figure 11. Flame wrinkles measurement in (a), (b) tumble induction and; (c), (d) swirl induction.

\section{Flame Distortion}

The measure of global change in the flame structure is called flame distortion [27, 32]. The computer programming code is developed to evaluate the flame distortion degree of the early flame by processing of the successive images taken in the region of ignition onset. The factors affecting the flame distortion of the early flame are the interaction with large-scale flow structures, the local quenching of the flame having contact with cold surfaces such as spark electrodes and the hydrodynamic strain effects of the in-cylinder bulk flow [33].

The flame distortion level was measured by the ratio of the flame perimeter to the perimeter of a circle whose radius is the equivalent radius of the flame. Similar techniques were used in the works of [6], [7], and [34]. To eliminate the influence of the small-scale local curvatures created by the wrinkles, a mean flame boundary was used for the calculation of flame distortion degree in the current work. Figure 12 shows early flame distortion measured by the techniques discussed earlier at the different engine operating speeds and induction flows for both stratified and homogeneous charge combustions. It was observed that the degree of flame distortion increased with an increase in engine operation speed in all engine operating conditions. This increase in the degree of flame distortion is as the result of the mean bulk velocity. Within the first $1.5 \mathrm{~ms}$ duration after the start of ignition, there was no significant global change in the shape of the flame observed especially in the tumble induction. Though insignificant, swirl intake showed higher flame distortion than the tumble intake. This might be due to the presence of largescale eddies near compression TDC in swirl intake configuration, because of its lower turbulence decaying rate compared to tumble induction. On the other hand, flame distortion behaviour did not show significant changes between the stratified and homogeneous charge combustion cases. 


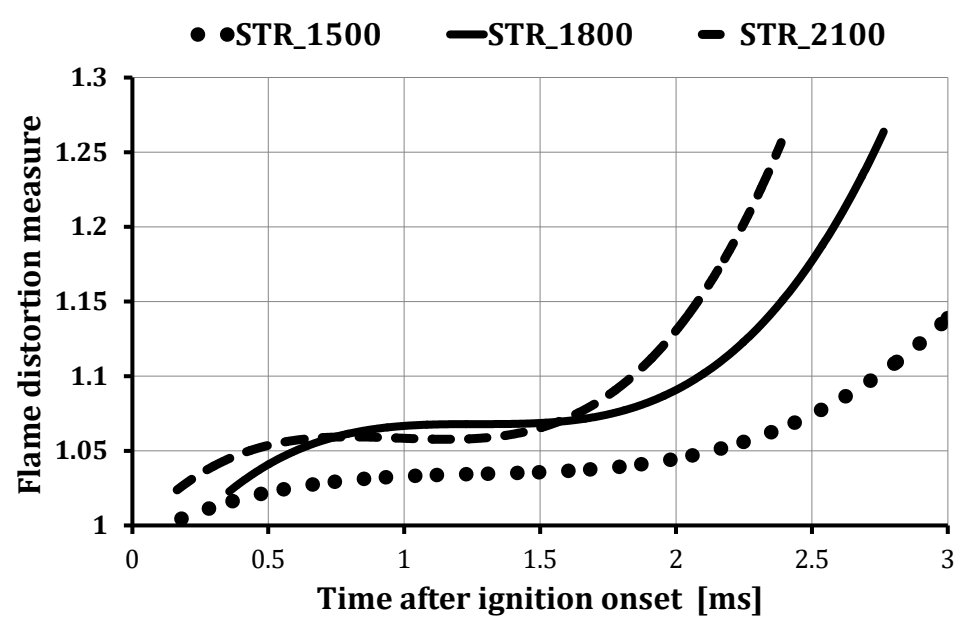

(a)

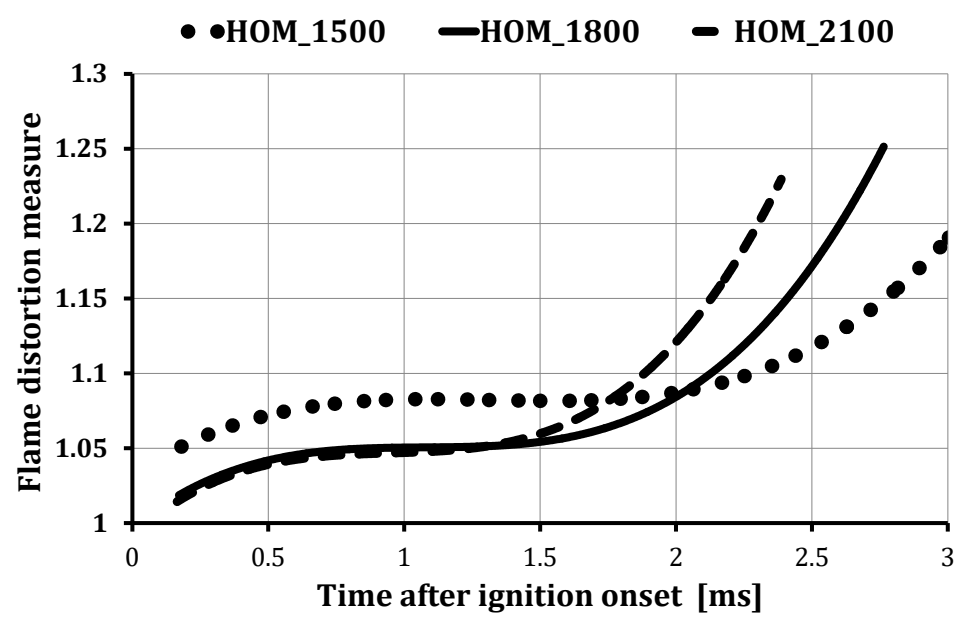

(b)

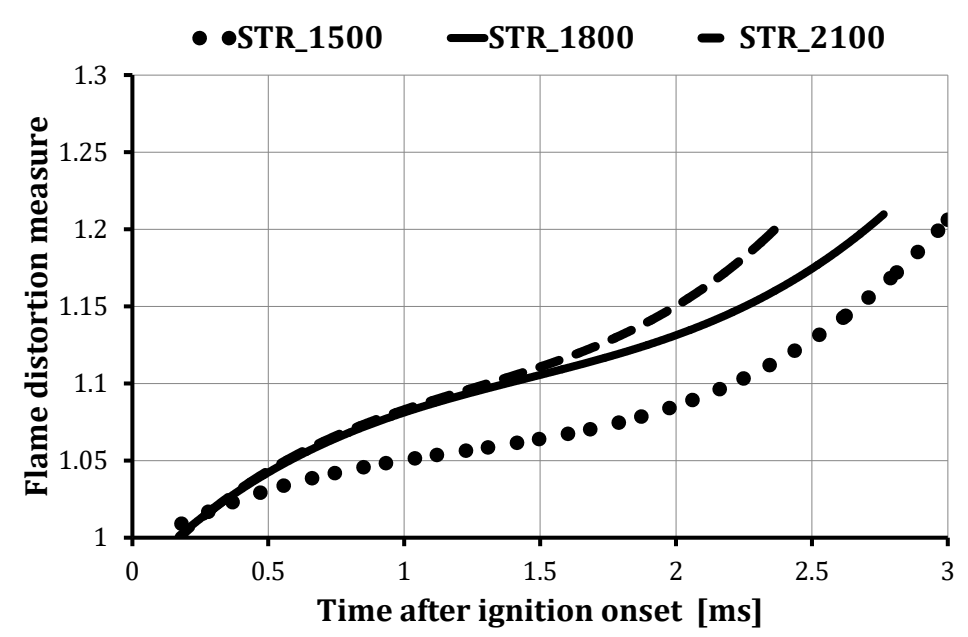

(c) 


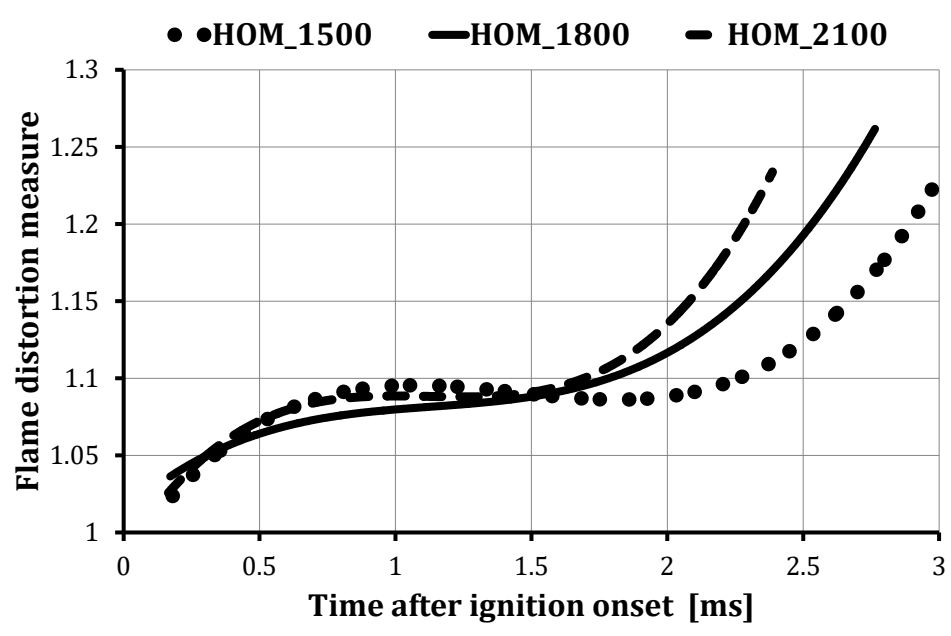

(d)

Figure 12. Flame distortion measurement in (a), (b) tumble induction and; (c), (d) swirl induction.

\section{Flame Growth Rate}

The rate of flame growth was measured by the rate of change of equivalent radius of the mean flame. The flame kernel growth rate varies with the wrinkles and distortion conditions of the flame. Wrinkles can increase flame surface area. As a result, burning rate increases. The flame growth rate can also be affected by the position of the small flame at the early stages of combustion. Contact of the flame kernel with the relatively cold surfaces, such as spark electrodes, quenches the small flame globally or locally. This might affect the growth rate of the early flame.

Figure 13 shows the average flame growth rate during the development period for stratified and homogeneous combustion cases. It can be observed in Figure 13 (a) that in the stratified charge combustion, tumble induction showed a better growth rate than the swirl induction especially with the rise in engine speeds. This report is supported by Gunasekaran and Ganesan [35] findings that showed tumble intake with the late injection would provide better mixture formation and combustion characteristics. The sequence of flame images within $2.4 \mathrm{~ms}$ after ignition onset for the tumble induction, stratified combustion at the highest engine speed of $2100 \mathrm{rpm}$.

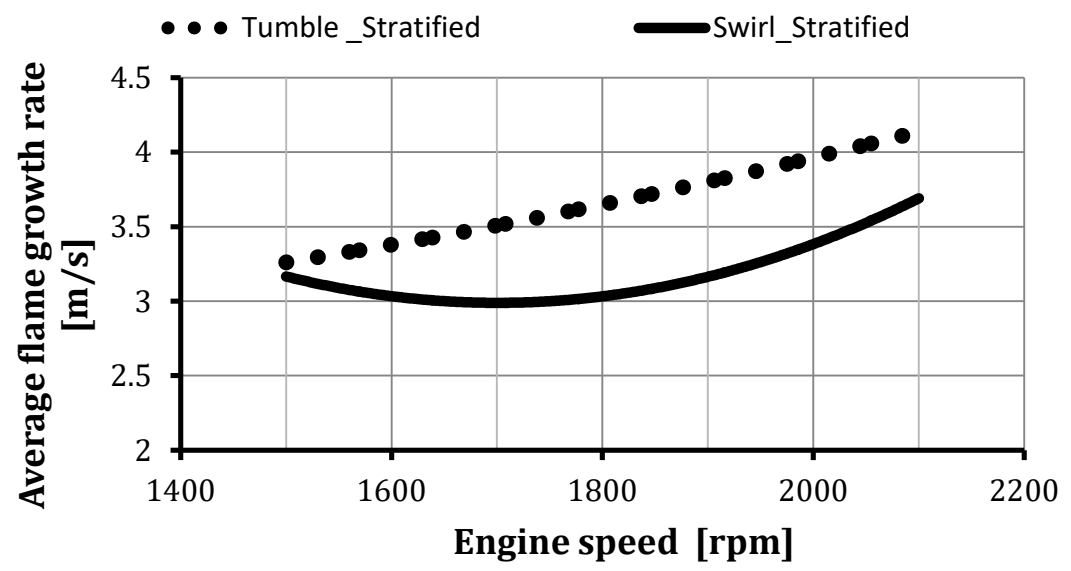

(a) 


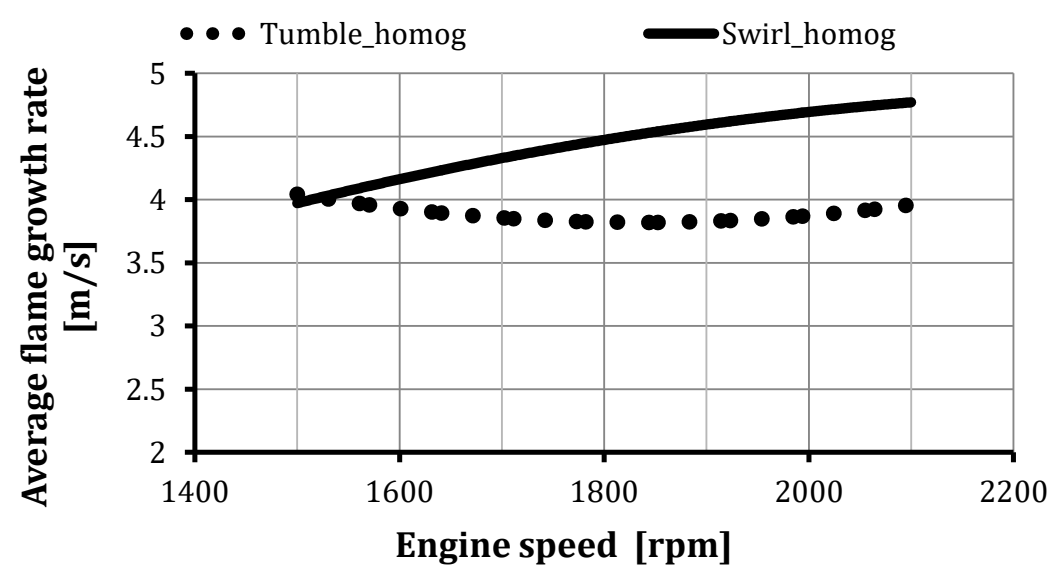

(b)

Figure 13. Average flame growth rate at the different engine parameters of (a) stratified charge combustion, (b) homogeneous charge combustion.

On the other hand, inhomogeneous charge combustion, swirl induction caused for the highest flame growth rate performance, whereas tumble induction showed almost no variation with change in engine speed as shown in Figure 13 (b). It was also observed that homogeneous swirl combustion had the fastest growing flame in the early combustion period, and the rate was increasing much more with engine speed.

\section{CONCLUSION}

Early flame characteristics of a CNG DI SI combustion was investigated using image processing and elliptic Fourier analysis methods. This technique was used to overcome the drawback of the conventional Fourier analysis method for the flame contour characterisation such as divisions being equal on the construction of contours, the method being dependent on coordinate and requirement of multi-valued function for defining of complex contours. The technique chosen was effective in the description of flame shape features for the approximation of wrinkled and mean flame boundaries; from which level of wrinkles, distortion and growth rate of the early flame obtained. This study summarises that the early flame growth rate depended not only on the intake configurations (tumble or swirl) but also on mixture level of stratification or homogeneity. The technique used in this work is found effective because of its simplistic algorithm to process multiple flame data automatically. It has overcome the limitations of the conventional Fourier analysis method to provide a quantitative flame description from the qualitative flame image.

\section{ACKNOWLEDGEMENT}

Authors would like to acknowledge Universiti Teknologi PETRONAS and Universiti Malaysia Pahang for the research facility and financial support through the research grant RDU1803164 and RDU160393. 


\section{REFERENCE}

[1] Lawal M, Abolarin M, Nasir A, Musa A. Differential air/fresh charge demand, supply and utilisation in two-stroke spark ignition engines. International Journal of Automotive and Mechanical Engineering. 2017;14:4769-.

[2] Arcoumanis C, Kamimoto T. Flow and combustion in reciprocating engines. Berlin: Springer; 2009.

[3] Lu G, Stasiak A, Shao J, Yan Y. Digital imaging based measurement of combustion flame characteristics. Imaging Systems and Techniques, 2007 IST'07 IEEE International Workshop on: IEEE; 2007. p. 1-4.

[4] He C, Kuenne G, Yildar E, van Oijen J, di Mare F, Sadiki A, et al. Evaluation of the flame propagation within an SI engine using flame imaging and LES. Combustion Theory and Modelling. 2017;21:1080-113.

[5] Winklhofer E, Philipp H, Fraidl G, Fuchs H. Fuel and flame imaging in SI engines. SAE Transactions. 1993:1263-72.

[6] Aleiferis PG, Taylor AMKP, Ishii K, Urata Y. The nature of early flame development in a lean-burn stratified-charge spark-ignition engine. Combustion and Flame. 2004;136:283-302.

[7] Ancimer R, Jaaskelainen H, Wallace J. Experiments into the Flame Kernel Development in High Swirl Production Spark Ignition Engine. SAE. 1999.

[8] Ancimer RJ. The influence of in-cylinder flows on the flame kernal growth in natural gas fuelled spark ignition engines: University of Toronto; 2000.

[9] Kerstein AR, Witze PO. Flame-Kernel Model for Analysis of Fiber-Optic Instrumented Spark Plug Data. SAE. 1990.

[10] Lord DL, Anderson RW, Brehob DD, Kim Y. The Effects of Charge Motion on Early Flame Kernel Development. SAE. 1993.

[11] Ikeda Y, Nakajima T, Ohira T. Flame propagation characteristics by planar $\mathrm{OH}$ Measurment. SAE Paper. 1999.

[12] Wang J, Huang Z, Tang C, Zheng J. Effect of hydrogen addition on early flame growth of lean burn natural gas-air mixtures. International Journal of Hydrogen Energy. 2010;35:7246-52.

[13] Aleiferis PG, Taylor AMKP, Whitelaw JH. Cyclic Variations of Initial Flame Kernel Growth in a Honda VTEC-E Lean-Burn Spark-Ignition Engine. SAE. 2000.

[14] Chala G, Aziz A, Hagos F. Combined effect of boost pressure and injection timing on the performance and combustion of CNG in a DI spark ignition engine. International Journal of Automotive Technology. 2017;18:85-96.

[15] Chala G, Abd Aziz A, Hagos F. Natural Gas Engine Technologies: Challenges and Energy Sustainability Issue. Energies. 2018;11:2934.

[16] Hagos FY, Aziz ARA, Sulaiman SA. Early flame development image comparison of low calorific value syngas and CNG in DI SI gas engine. IOP Conference Series: Earth and Environmental Science: IOP Publishing; 2013. p. 012070.

[17] Aziz ARA, Shahzad R. Combustion analysis of a CNG direct injection spark ignition engine. International Journal of Automotive and Mechanical Engineering. 2010;2:157-70.

[18] Sezgin M, Sankur B. Survey over image thresholding techniques and quantitative performance evaluation. Journal od Electronic Imaging. 2004;13:146-65.

[19] Otsu N. A threshold selection method from Gray level Histogram. IEEE transactions. 1979;9:62-5 
[20] Nacereddin N, Hamami L, Tridi M, Oucief N. Non-parametric Histogram-based thresholding methods for weld defect detection in radiography. Worl Academy of Science, Engineering and Technology. 2005;9.

[21] Neto JC. A combined statistical-soft computing approach for classification and mapping weed species in minimum-tillage system. Lincoln: University of Nebraska; 2004.

[22] Kuhl FP, Giardina CR. Elliptic Fourier features of a closed contour. Computer Graphics and Image Processing. 1982;18:236-58.

[23] Neto JC, Meyer GE, Jones DD, Samal AK. Plant species identification using elliptic Fourier leaf shape analysis. Computers and electronics in agriculture. 2006;50:121-34.

[24] Tort A. Elliptic Fourier functions as a morphological descriptor of the genus Stenosarina (Brachiopoda, Terebratulida, New Caledonia. International Association for Mathematical Geology. 2003;35:873-85.

[25] Le Minor JM, Schmittbuhl M. Importance of elliptic Fourier methods for morphometry of complex outlines: application to the distal human femur. Surgical and Radiologic Anatomy. 1999;21:387-91.

[26] Freeman $\mathrm{H}$. On the encoding of arbitrary geometric configurations. IRE Transactions on Electronic Computers. 1961;2:260-8.

[27] Aziz ARA, Anbese YT, Hagos FY, Heikal MR. Characteristics of Early Flame Development in a Direct-Injection Spark-Ignition CNG Engine Fitted with a Variable Swirl Control Valve. Energies. 2017;10:964.

[28] Nixon MS, Aguado AS. Feature extraction and image processing. $2^{\text {nd }}$ ed. Oxford: Academic Press; 2008.

[29] Heim D, Ghandhi J. A detailed study of in-cylinder flow and turbulence using PIV. SAE Paper. 2011.

[30] Andwari AM, Aziz AA, Said MFM, Esfahanian V, Latiff ZA, Said SNM. Effect of internal and external EGR on cyclic variability and emissions of a spark ignition two-stroke cycle gasoline engine. Journal of Mechanical Engineering and Sciences. 2017;11:3004-14.

[31] Ting D, Checkel M, Johansson B. The importance of high frequency, small eddy turbulence in spark ignited, premixed engine combustion. SAE. 1995.

[32] Merola SS, Tornatore C, Irimescu A, Marchitto L, Valentino G. Optical diagnostics of early flame development in a DISI (direct injection spark ignition) engine fueled with n-butanol and gasoline. Energy. 2016;108:50-62.

[33] Samaniego JM, Mantel T. Fundamental Mechanisms in Premixed Turbulent Flame Propagation via Flame-Vortex Interactions. Combustion and Flame 1999;118:537-56

[34] Gillespie L. Imaging and analysis of turbulent flame development in spark ignition engines. Leeds: University of Leeds; 1998.

[35] Gunasekaran J, Ganesan V. Effect Of Swirl and Tumble on the Stratified Combustion of a DISI Engine - A CFD Study. SAE Paper. 2011. 